\title{
Construtivismo: experiência metodológica em pesquisa na enfermagem*
}

\author{
Constructivism: methodological experience in nursing research
}

Constructivismo: experiencia metodológica en investigación de enfermería

\author{
Maira Buss Thofehrn', Maria Tereza Leopardi², Simone Coelho Amestoy ${ }^{3}$
}

\begin{abstract}
RESUMO
Objetivo: Este estudo teve o objetivo de socializar a experiência metodológica de uma pesquisa construtivista, sob os preceitos de Vygotsky quanto ao ensino-aprendizagem e Rodwell como estratégia investigativa. Métodos: O construtivismo busca a interação do sujeito-objeto com o meio ambiente. Essa estratégia foi utilizada para construção de um modelo para formação e afirmação de vínculos profissionais saudáveis, junto à equipe de enfermagem. O critério de confiabilidade adotado foi a triangulação na obtenção dos dados: entrevista semiestruturada, observação simples e grupo focal. Resultados: É gratificante trabalhar com a metodologia e a teoria em questão, em virtude do respeito pelo sujeito pesquisado e flexibilidade do pesquisador. É relevante a utilização da triangulação, pois cada técnica utilizada complementa as brechas e assim alcança-se o objetivo do estudo. Conclusão: O investigador, apesar da responsabilidade pelo resultado da pesquisa, consegue efetuar um estudo participativo mediante uma construção coletiva.
\end{abstract}

Descritores: Pesquisa em enfermagem; Conhecimento

\begin{abstract}
Objective: This study aimed to socialize the methodological experience of a constructivist research, based on Vygotsky's rules of teachinglearning and Rodwell as a research strategy. Methods: Constructivism aims for the subject-object's interaction with the environment. This strategy was used to construct a model for the formation and affirmation of healthy professional bonds in the nursing team. Triangulation in data collection was used as a reliability criterion: semi-structured interview, simple observation and focus group. Results: It is rewarding to work with this methodology and theory, due to the respect for the research subject and the researcher's flexibility. The use of the triangulation is relevant because each technique used complements the gaps, so that the study objective is reached. Conclusion: Despite the responsibility for the research results, the researcher manages to carry out a participatory study through collective construction.
\end{abstract}

Keywords: Research in nursing; Knowledge

\section{RESUMEN}

Objetivo: En este estudio se tuvo como objetivo socializar la experiencia metodológica de una investigación constructivista, bajo los preceptos de Vygotsky en cuanto a la enseñanza-aprendizaje y Rodwell como estrategia investigativa. Métodos: El constructivismo busca la interacción del sujeto-objeto con el medio ambiente. Esa estrategia fue utilizada para la construcción de un modelo para la formación y afirmación de vínculos profesionales saludables, con el equipo de enfermería. El criterio de confiabilidad adoptado fue la triangulación en la obtención de los datos: entrevista semi-estructurada, observación simple y grupo focal. Resultados: Es gratificante trabajar con la metodología y la teoría en cuestión, en virtud del respeto por el sujeto investigado y la flexibilidad del investigador. Es relevante la utilización de la triangulación, pues cada técnica utilizada complementa las brechas y así puede alcanzarse el objetivo del estudio. Conclusión: el investigador, a pesar de la responsabilidad por el resultado de la investigación, consigue efectuar un estudio participativo mediante una construcción colectiva.

Descriptores: Investigación en enfermería; Conocimiento

\footnotetext{
*Esse estudo é parte da tese de doutorado "Vinculos Profissionais: uma proposta para o trabalho em equipe na enfermagem" defendida em fevereiro de 2005, na Universidade Federal de Santa Catarina - UFSC - Florianópolis (SC), Brasil.

${ }^{1}$ Doutora, Professora da Faculdade de Enfermagem e Obstetricia da Universidade Federal de Pelotas - UFPEL - Pelotas (RS), Brasil.

${ }^{2}$ Doutora, Coordenadora do Curso de Enfermagem da Universidade do Extremo Sul Catarinense - UNESC - Criciúma (SC), Brasil.

3 Especialista em Enfermagem com Ênfase em Terapia Intensiva pela Associação Hospitalar Moinhos de Vento - Porto Alegre (RS), Brasil.
} 


\section{INTRODUÇÃO}

A corrente construtivista do pensamento, a partir das idéias de Vygotsky com ênfase no ensino-aprendizagem e Rodwell, abordagem metodológica, foi a estratégia utilizada na pesquisa para a construção de um modelo para formação e afirmação de vínculos profissionais saudáveis, no qual o processo de trabalho em equipe na enfermagem possa ocorrer de modo a favorecer um cuidado que atenda, tanto as pessoas necessitadas, quanto às responsabilidades ético-morais dos profissionais.

A estratégica metodológica numa investigação científica corresponde ao instrumento para o enfrentamento da realidade $^{(1)}$, que na pesquisa em questão teve uma abordagem qualitativa, ao responder questões particulares, preocupandose com os aspectos que não podem ser quantificados, pois trabalhamos com um universo de significados, valores e atitudes. Sob esse foco, o construtivismo foi selecionado para alcançar o objetivo de criar um modelo de trabalho com vistas a contribuir para o redimensionamento da identidade gerencial do enfermeiro, na busca pela valorização e visibilidade dos próprios profissionais, mediante a prestação de um cuidado de qualidade e que atenda as pessoas em suas reais necessidades.

Ainda, o construtivismo foi à opção escolhida por ser um método alternativo que busca a flexibilidade e adaptação, que expõe a sensibilidade da relação entre o investigador e os pesquisados, partindo da interação entre o racional e o intuitivo na análise do fenômeno, tendo como meta a precisão, concomitante ao artístico ${ }^{(2)}$. Desta forma, esse artigo teve como objetivo socializar e compartilhar a experiência da trajetória metodológica de uma pesquisa construtivista, sob os preceitos de Vygotsky e de Rodwell, oferecendo, também, uma reflexão acerca do comportamento humano em constante influência e interrelações com o contexto histórico, cultural e social, identificando o trabalho como um importante meio de relacionamento entre as pessoas e a natureza, determinando linhas alternativas de investigação de um fenômeno ${ }^{(3)}$.

\section{MÉTODOS}

Este estudo está pautado na metodologia construtivista sob a ótica vygotskiana, com algumas contribuições desse conhecimento para a enfermagem, e a experiência do construtivismo como estratégica metodológica de pesquisa, mediante as idéias de Rodwell. Na pesquisa construtivista o ser humano, enquanto um ser social e histórico, é responsável em manter ou transformar o contexto no qual se insere. Assim, é rejeitada a possibilidade de neutralidade por parte do investigador, bem como do ambiente pesquisado $^{(4)}$. Para a investigação em questão, o foco é a formação de uma equipe de enfermagem, com formação de vínculos profissionais saudáveis.
No construtivismo o rigor e a qualidade dependem da confiabilidade, da autenticidade e, obrigatoriamente, devem beneficiar a todos os envolvidos na investigação( ${ }^{(5)}$. Com vistas a atender tais exigências foi adotada a triangulação de técnicas na coleta de dados, ou seja, entrevista semi-estruturada, observação simples e grupo focal, o que correspondeu, respectivamente, às três fases dessa trajetória metodológica: entrevista, observação e construção. Assim, o mesmo fenômeno foi examinado sob várias perspectivas, o que determinou a expansão do entendimento acerca da situação investigada ${ }^{(6)}$.

O projeto foi aprovado pelo Comitê de Ética em Pesquisa da Faculdade de Medicina da Universidade Federal de Pelotas, ofício n. ${ }^{\circ} 060 / 2002$. Os demais aspectos éticos respeitaram a Resolução $n^{\circ} 196 / 96^{(7)}$ do Ministério da Saúde, que trata da pesquisa envolvendo seres humanos e estiveram presentes desde a seleção dos participantes e durante as três etapas da pesquisa. Após a assinatura individual do consentimento livre e esclarecido, foi garantido sigilo e anonimato, bem como acesso aos dados e liberdade de desistir do estudo quando o desejassem, os participantes receberam codificação por meio de nome de flores, a seu critério de escolha.

\section{RESULTADOS}

Frente ao objetivo desse estudo de socializar a experiência metodológica de uma pesquisa construtivista e, de contribuir na instrumentalização de profissionais com interesse em utilizar essa corrente do conhecimento apresentamos a seguir as fases da execução do processo investigativo em questão.

Fase de entrevista: percepção dos enfermeiros acerca das relações interpessoais na equipe de enfermagem

Sendo uma pesquisa interativa, fez-se necessário ter um real entendimento acerca da percepção dos enfermeiros, quanto às relações interpessoais na equipe de enfermagem, com vistas a auxiliar no planejamento das fases posteriores. Os dados da fase de entrevista foram colhidos durante o mês de setembro de 2001, quando entrevistamos enfermeiros que desenvolvem suas atividades profissionais em três hospitais gerais e em uma escola de enfermagem, numa cidade do interior da região Sul do Brasil, num total de doze participantes, sendo três de cada entidade. Os preceitos éticos foram respeitados durante o transcorrer desta fase. A entrevista foi gravada, realizada no próprio contexto de trabalho e validada pelo participante logo em seguida, após ouvir a gravação. Após, a mesma foi transcrita na íntegra, as respostas agrupadas e classificadas, conforme seu conteúdo, esse material serviu, também, como subsídio para planejamento e realização das fases subseqüentes. 
Fase de observação: processo de trabalho em equipe na enfermagem

$\mathrm{Na}$ investigação construtivista a interação social é fundamental, pois a pessoa internaliza os elementos de sua cultura, construindo seu universo intra-psicológico, a partir do mundo externo. Em geral, a pessoa não o manifesta em seu discurso, durante uma entrevista por serem inconscientes, porém pode expressá-lo em suas ações ${ }^{(8)}$. Desta forma, mediante a técnica de observação simples foi possível um contato direto e uma visão mais ampla das relações culturais e sociais da equipe de enfermagem. Três equipes de enfermagem foram observadas, no período de outubro a dezembro de 2002, uma de cada vez. A observação ocorreu durante períodos intermitentes de duas horas, e registros subseqüentes, em diferentes turnos de trabalho, totalizando 35 horas de observação. Nos meses de janeiro e fevereiro de 2003, já com os dados colhidos e descritos num diário de campo, os mesmos foram apreciados por todos os participantes das equipes observadas e validados.

Fases de construção: modelo para o trabalho em equipe na enfermagem

Nesta fase, foi utilizada a técnica de grupo focal, entendida como um modo de coletar dados a partir das experiências, discussões, percepções em grupo, no qual o interesse não está na busca de informações individuais e sim no resultado obtido, a partir de um amplo debate no grupo ${ }^{(9)}$.

Visando promover o processo de construção do modelo para o trabalho em equipe na enfermagem e no intuito de atender as recomendações da pesquisa construtivista, os participantes foram selecionados de modo a preencher os critérios para a obtenção do máximo de dados variáveis sobre a realidade estudada ${ }^{\left({ }^{(}\right)}$. Foram convidados a participar do grupo enfermeiros e profissionais de nível médio, com experiência de no mínimo cinco anos, junto às equipes de enfermagem e acadêmicos de enfermagem com interesse na área em pauta, formando assim uma amostra intencional.

O grupo contou com a inscrição e participação de 16 componentes no primeiro encontro. Como era de se esperar, o grupo teve $35 \%$ de desistência, permanecendo efetivamente, dez pessoas com $60 \%$ de freqüência mínima, assim distribuída: oito enfermeiros, um auxiliar de enfermagem e um acadêmico de enfermagem, contemplando, assim a recomendação de participantes por grupo focal que devem ser, idealmente, entre seis e quinze pessoas ${ }^{(9-10)}$.

A fase de construção contou com o desenvolvimento de três etapas: primeira etapa: estudo e construção do modelo para o trabalho em equipe na enfermagem; segunda etapa: parada reflexiva; terceira etapa: validação do modelo para o trabalho em equipe na enfermagem.

Primeira etapa: foi desenvolvida através de dez encontros, que ocorreram de abril a julho de 2003, em local e horário fixo e pré-determinado, cada encontro teve duração de três horas.

Segunda etapa: correspondeu ao período de reflexão, em que foi realizada uma pausa proposital de dois meses, visando favorecer a internalização dos conhecimentos adquiridos durante a primeira etapa ${ }^{(4)}$.

Terceira etapa: foram realizados dois encontros para validação do modelo para o trabalho em equipe na enfermagem, construído pelo grupo focal, o mesmo foi aprovado.

Validação dos dados através da triangulação de técnicas metodológicas

Após uma análise mais apurada dos dados colhidos durante a realização das três técnicas, entrevista, observação e grupo focal, o modelo para o trabalho em equipe na enfermagem foi reelaborado e, então, apresentado e discutido em dois encontros, para ser validado. Foram convidados todos os participantes da primeira, segunda e terceira fases da coleta de dados e alguns profissionais com experiência de atuação em equipes. Em ambos os encontros o modelo foi amplamente discutido e aprovado por unanimidade.

\section{Análise dos dados}

A análise dos dados correspondeu a uma trajetória complexa de organização e interpretação dos dados, que acompanhou toda a experiência metodológica. $\mathrm{Na}$ medida em que os dados foram sendo colhidos, procuramos identificar os temas e a cada nova interpretação ou complementação, esses dados sofreram redimensionamentos, numa contínua reelaboração dos mesmos, com vistas a responder o objetivo do trabalho. Após o término do processo de análise, o qual superou as nossas expectativas, passamos à realização do relatório final.

\section{Síntese dos dados em direção à Teoria dos Vínculos Profissionais}

A síntese se constituiu do esforço reflexivo para a articulação dos conceitos propostos, já que os dados obtidos foram além da elaboração do modelo para o trabalho em equipe na enfermagem, assim buscamos dar um formato sistematizado e lógico a esses conceitos.

$\mathrm{O}$ modo de fazer esse procedimento se estruturou em torno do propósito deste estudo, ou seja, as relações interpessoais, a partir da perspectiva dialética e histórica, buscando ir do microespaço à comunidade social, da parte ao todo, para finalizar com uma proposta prática, na formulação de uma ferramenta gerencial para o desenvolvimento de vínculos profissionais saudáveis na equipe de enfermagem. 


\section{DISCUSSÃO}

Como mencionado, até o presente momento é possível compreender o salto qualitativo que objetivamos mediante a utilização da metodologia construtivista, mas foram às idéias de Vygotsky que permitiram reagrupar os conceitos emergidos dos dados e sistematizá-los enquanto uma teoria.

Cabe ressaltar que a abordagem vygotskiana está pautada nos princípios do materialismo histórico e do método dialético, na identificação das mudanças qualitativas do comportamento, presentes ao longo do desenvolvimento do ser humano e sua relação com o contexto social, cujo foco central está nas funções psicológicas superiores que se originam da realidade sócio-cultural e emergem de processos psicológicos elementares, de ordem biológica, isto é, estruturas orgânicas, enquanto elucidação para o entendimento do processo de ensino-aprendizagem.

As funções psicológicas superiores, conforme Vygotsky diferem dos processos psicológicos elementares, visto que esses estão presentes nas crianças pequenas e nos animais, e correspondem às reações automáticas, ações reflexas e associações simples, que são de origem biológica. Já as funções psicológicas superiores consistem na capacidade própria dos seres humanos de planejamento, memória voluntária, imaginação, referemse a mecanismos intencionais, ações conscientemente controladas e processos voluntários. Estes processos não são inatos, ocorrem a partir das relações entre as pessoas, desenvolvendo-se ao longo do processo de internalização de formas culturais de comportamento ${ }^{(8)}$.

Vygotsky parte da compreensão de que entre o sujeito e o objeto, existe um artefato mediador a partir desse triângulo básico ocorre o processo de aprendizagem. $\mathrm{O}$ ser humano, enquanto, sujeito deve ser considerado em sua dimensão plural, envolvendo o psiquismo humano, o gênero social e o papel das diferentes culturas no desenvolvimento das funções psicológicas superiores. A pessoa é entendida como um ser construído mediante suas próprias condições de existência, faz-se na história e, concomitantemente, faz essa história. O objeto é entendido como o ambiente social e histórico estabelecido, enquadrando-se na vertente sócio-interacionista, na qual a teia de relações sociais é o ponto central ${ }^{(11)}$. $\mathrm{O}$ artefato mediador consiste no processo de mediação, ou seja, refere-se à capacidade do ser humano em manter uma interação recíproca e constante consigo mesmo e com as outras pessoas. É justamente a partir desse caráter de mediação que se desenvolvem as funções psicológicas superiores, já que a relação do ser humano com o mundo não é uma relação direta.

A mediação ocorre por meio de artefatos mediadores, que podem ser de duas naturezas: física ou material, que altera o meio físico e o sujeito da ação, sendo instrumentos por meio de ações concretas; representacional ou de signos que compreendem os instrumentos psicológicos que atuam nas questões internas da pessoa ${ }^{(12)}$. No estudo em questão, o modelo para o trabalho em equipe na enfermagem que emergiu dos dados corresponde a um artefato mediador represental, pois insere-se na dimensão da subjetividade do sujeito-trabalhador.

Para facilitar a compreensão acerca dos signos, fizemos uma analogia frente à realidade prática da enfermagem ao nos reportarmos a um curativo, no qual podemos lidar mentalmente com esse objeto ou situação ou até mesmo na sua ausência. Assim, quando pensamos em um curativo, não temos na mente o próprio curativo, trabalhamos com uma idéia, um conceito, uma imagem, uma palavra, enfim, algum tipo de representação, de signo, que substitui o curativo real sobre o qual pensamos.

Essa capacidade de usar as representações, para substituir o próprio real é que possibilita ao ser humano libertar-se do espaço e do tempo atual, fazer relações mentais na falta das próprias coisas, imaginar, planejar e ter intenções, o que nos leva a pensar num curativo pequeno ou grande, limpo ou sujo, oclusivo ou aberto. Essas possibilidades de operação mental não consistem numa relação direta com o mundo palpável, pois é determinada por uma relação mediada pelos signos internalizados, libertando as pessoas da necessidade de interação concreta com os objetos de seu pensamento.

Uma das propriedades do signo é propiciar e levar à significação. Novamente, ao nos reportarmos ao curativo, cada enfermeiro, terá a sua significação, o seu significado com relação a esse procedimento, alguns dão uma ênfase maior ao fator estético, outros nem tanto, já que a significação irá depender das relações sociais estabelecidas por esse profissional, sua aprendizagem no contexto familiar, vida acadêmica, ambiente de trabalho, entre outros.

Desta forma, o desenvolvimento do ser humano, enquanto um ser consciente ocorre a partir da internalização, isto é, na apropriação pelo sujeito das conquistas e conhecimentos produzidos historicamente e originado nas relações sociais, além da utilização dos sistemas simbólicos - pensamento e linguagem ${ }^{(13)}$.

Fazendo um paralelo com o que foi abordado, constatamos que a equipe de enfermagem está normalmente, inserida numa instituição de saúde e desenvolve ações sistemáticas, têm uma intencionalidade deliberada e compromisso explícito, legitimado historicamente, de prestar um cuidado à pessoa necessitada. Tem como foco central à teia das relações intrapessoais, na formação das particularidades pessoais e individuais e relações interpessoais, tanto com o cliente, quanto entre si, dentro da própria equipe e com a equipe multidisciplinar. 
Nesse contexto, os membros da equipe são desafiados a entender as concepções científicas e a tomar consciência de seus próprios processos mentais, com vistas a prestar um cuidado diferenciado e particularizado a cada pessoa. As atividades desenvolvidas e os conceitos presentes no desenvolvimento da prática profissional, quando refletidos e discutidos, introduzem novos modos de operação intelectual, com abstrações e generalizações mais amplas acerca da realidade e do próprio processo de trabalho. Como conseqüência, expandem seus conhecimentos, modificando sua relação com o mundo, levando à visualização da própria ação, ou seja, um cuidado que favoreça o desencadeamento da valorização e da autonomia profissional.

Assim, na perspectiva vygotskiana, para se construir uma ordem social justa, faz-se necessário o rompimento com o modelo vigente de verdades estanques e práticas rotineiras. Essa ruptura com a realidade vigente é possível, mediante a existência de estratégias de mudanças, pelo processo de desenvolvimento mental do ser humano. Através da dimensão da subjetividade, de questões que evoluem para diferenças de julgamento, valores e percepções é possível identificar meios para uma mensuração alternativa do valor do produto do trabalho na enfermagem ${ }^{(14)}$.

Cabe ressaltar que, para explicar essa evolução intelectual, Vygotsky desenvolveu o conceito de Zona de Desenvolvimento Proximal, a qual é caracterizada por saltos qualitativos de um nível de conhecimento para outro, correspondendo à base do processo de ensinoaprendizado do ser humano(5).

\section{CONSIDERAÇÕES FINAIS}

Com o desafio de olhar para a equipe de enfermagem e vislumbrar um ambiente de trabalho

\section{REFERÊNCIAS}

1. Minayo MCS. O desafio do conhecimento: pesquisa qualitativa em saúde. 7a. ed. São Paulo: Hucitec/Abrasco; 2000.

2. Rodwell MK. Social work constructivist research. New York/London: Garland Publishing; 1998.

3. Rego TC. Vygotsky: uma perspectiva histórico-cultural da educação. 11a ed. Petrópolis: Vozes; 2001.

4. Vigotsky LS. A construção do pensamento e da linguagem. São Paulo: Martins Fontes; 2001.

5. Rodwell MK. Um modelo alternativo de pesquisa: o construtivismo. Rev FAEEBA. 1994; 3(1):125-41.

6. Leopardi MT. Critérios de confiabilidade e validez. In: Leopardi MT, et al. Metodologia da pesquisa na saúde. Santa Maria: Pallotti; 2001. p. 25-256.

7. Brasil. Ministério da Saúde. Conselho Nacional de saúde. Normas de pesquisa envolvendo seres humanos - Res. CNS 196/96. Bioética. 1996; 4(2 Supl): 15-25.

8. Vygotsky LS. Formação social da mente: o prazeroso, além da formação de um grupo em busca de propostas inovadoras, para a execução da tarefa profissional, embarcamos nessa jornada científica, através da abordagem construtivista, com base vygotskiana.

Desta forma, ousamos construir uma ferramenta mediadora, um modelo para o trabalho em equipe na enfermagem, considerando a dimensão da subjetividade no trabalho, pela corrente da dinâmica das relações interpessoais. Para nossa surpresa, além de atingir o objetivo proposto da pesquisa, foi possível superá-lo, pois ao nos depararmos com os dados coletados, vimos emergir um conjunto de conceitos e estratégias gerais, flexíveis e interdependentes que nos levaram a pensar na perspectiva de uma teoria dos vínculos profissionais.

Acreditamos que um dos fatores para o surgimento da teoria se deve a utilização da triangulação na coleta de dados, ou seja, entrevista, observação e grupo focal, pois possibilitou aprofundar o entendimento da situação investigada, pelo preenchimento das brechas encontradas em uma ou outra técnica, o que favoreceu e assegurou a confiabilidade dessa pesquisa construtivista.

A experiência adquirida com a presente investigação foi significativa, pois vivenciamos, durante todo o processo de pesquisar a contínua construção e reconstrução do conhecimento. Nesse processo, os conceitos adquiridos ao longo de nossa experiência profissional, junto às relações interpessoais na equipe de enfermagem, foram redimensionados e redefinidos e, enquanto pesquisadores construtivistas, interagimos com os pesquisados, determinando uma trajetória investigativa caracterizada por mudanças e transformações. Esse processo construtivista desencadeou, nos investigadores, a interiorização do construído e, assim levou à exteriorização, por meio das palavras e das ações, da teoria dos vínculos profissionais.

desenvolvimento dos processos psicológicos superiores. 6a ed. São Paulo: Martins Fontes; 1998.

9. Beck CLC, et al. Técnicas e procedimentos de pesquisa qualitativa. In: Leopardi MT, et al. Metodologia da pesquisa na saúde. Santa Maria: Pallotti; 2001. p. 257-81.

10. Dall'Agnol CM, Trench MH. Grupos focais como estratégia metodológica em pesquisas na enfermagem. Rev Gauch Enferm. 1999; 20(1):5-25.

11. Palangana IC. Desenvolvimento e aprendizagem em Piaget e Vygotsky: a relevância do social. 2a ed. São Paulo: Plexus Editora; 1998.

12. Oliveira MK. Vygotsky: aprendizado e desenvolvimento, um processo sócio-histórico. 4a. ed. São Paulo: Scipione; 2001.

13. Baquero R. Vygotsky e a aprendizagem escolar. 2a ed. Porto Alegre: Artes Médicas; 2001.

14. Mello MC, Fugulin FMT, Gaidzinski RR. O tempo no processo de trabalho em saúde: uma abordagem sociológica. Acta Paul Enferm. 2007; 20(1): 87-90. 